\title{
Borulu Sulama Şebekeleri Optimizasyonu
}

\author{
Gökhan MARIM' \\ Yakup DARAMA ${ }^{2}$ \\ Zafer BOZKUŞ ${ }^{3}$
}

\section{ÖZ}

Borulu sulama şebekeleri ülkelerin tarımsal ürün yetiştirmesinde ve su tasarrufunda en önemli sistemlerdir. Günümüzde tarımsal amaçlı sulama, su tüketiminin en yüksek olduğu sektördür. Ülkemizde tarım sektörünün kullandığı su miktarı su potansiyelimizin \%73 oranındadır. Ülkemizde ve genelde Dünyada nüfus artışı nedeniyle tarımsal üretimde su talebinin artması ve su kaynaklarımızın sınırlı olması nedeniyle sürdürülebilir su kaynakları yönetimi zorunlu olmaktadır. Son yıllarda ülkemizde yapılan sulama sistemleri yatırımlarının büyük bir çoğunluğunu, su kaybını ve tarımsal su kullanımını azaltan modern borulu sulama şebekeleri yatırımları oluşturmaktadır. $\mathrm{Bu}$ çalışma borulu sulama şebekelerinin tasarımlarının maliyet ve istenen işletme basınçları açısından optimum koşullara ulaşmasına odaklanmıştır. Optimizasyon problemi çözümünde heuristik tabanlı dinamik programlama ile birlikte doğrusal programlama yöntemi olan "Simplex" metodu kullanılmış olup, bu optimizasyon yazılımı DSİ borulu sulama şebekeleri için uygulanmıştır.

Anahtar Kelimeler: Sulama, borulu şebeke, optimizasyon, doğrusal programlama, simplex metodu.

\begin{abstract}
Optimization of Pipe Irrigation Networks

Pipe irrigation networks are the most important systems regarding a country's agricultural production and water conservation efforts. Today, irrigation for agriculture is the sector that leads to highest water consumption. The amount of water used by the agricultural sector in our country is $73 \%$ of our total water potential. Sustainable water resources management is mandatory because of the increase in water demand in agricultural production due to the population increase in our country and generally in the world and the limited water resources that exist. Irrigation systems constructed in our country in recent years constitute a great majority of investments, modern piped irrigation networks reduce water loss and economise
\end{abstract}

Not: Bu yazı

- Yayın Kurulu'na 21.04.2017 günü ulaşmıştır. 30.01.2018 günü yayımlanmak üzere kabul edilmiştir.

- 30 Kasım 2018 gününe kadar tartışmaya açıktır.

- DOI: $10.18400 /$ tekderg. 306880

1 Orta Doğu Teknik Üniversitesi, Jeodezi ve CBT Ana Bilim Dalı, Ankara -marim@sufen.com.tr

2 Atılım Üniversitesi, İnşaat Mühendisliği Bölümü, Ankara - yakup.darama@atilim.edu.tr

3 Orta Doğu Teknik Üniversitesi, İnşaat Mühendisliği Bölümü, Ankara- bozkus@metu.edu.tr 
agricultural water use. This work focuses on achieving optimum conditions for the design of pipe irrigation networks in terms of cost and desired operating pressures. In order to solve the optimization problem, heuristic based dynamic programming and "Simplex Method" which is a linear programming method were used and the software of these optimizations were applied to State Hydraulic Works (DSI) pipe irrigation networks.

Keywords: Irrigation, pipe network, optimization, linear programming, simplex method.

\section{GİRİş}

Borulu sulama şebekeleri ülkelerin tarımsal ürün yetiştirmesinde en önemli sistemlerdir. Günümüzde tarımsal amaçlı sulama, ülkemizde su tüketiminin en yüksek olduğu sektördür. Gelişmişliğin artması ile bu oran azalmakta ancak endüstriyel su kullanım oranı artmaktadır. İstenen miktarda ve istenen kalitede suyu toprakla buluşturmak sulama sistemlerinden beklenen en önemli işlevdir. Nüfus ve nüfus artışına bağlı gıda talebinin artması nedeniyle tarımsal alan miktarı artmıştır. Bu durum tarımsal amaçlı kullanılan su miktarını da arttırmıştır. Su kaynaklarının limitsiz olmaması ve suya talebin hızla artışı, sadece tarım sektöründe değil diğer sektörlerde de artması, sürdürülebilir su kaynakları yönetimini zorunlu hale getirmektedir. Tarımsal amaçlı sulamada kullanılan su miktarını azaltmak, tarımsal sulama sistemlerini verimli ve etkin bir şekilde kullanmak önemli bir konu haline gelmiştir. Ülkemizde su kullanım sektörleri arasında tarımsal sulamada kullanılan su miktarı \%73 oranındadır [5]. Dünya ortalaması da \%70 mertebesindedir. Gelişmiş ülkelerde ise bu oran $\% 30$ iken endüstride kullanılan su miktarı \%59 oranındadır.

Ülkemizde yıllık ortalama 32 milyar $\mathrm{m}^{3}$ su tarım (\%73) sektöründe, 5 milyar $\mathrm{m}^{3}$ (\%11) endüstride, 7 milyar $\mathrm{m}^{3}$ (\%15) içmesuyunda kullanılmaktadır [8]. Türkiye'de sulanan alan 4.9 milyon hektar (ha) olup, bu miktar toplam ekonomik olarak sulanabilir 8 milyon ha tarımsal alanın yaklaşık olarak \%63'ünü oluşturmaktadır [9]. Türkiye'de son yıllarda sulama sektöründe önemli gelişmeler yaşanmakta olup, birçok bölgede borulu sulama şebeke yatırımı gerçekleştirilmektedir. Borulu sulama şebekeleri, hem tarımda sulama suyu kullanımını azaltmakta hem de tarımsal verimi arttıran modern sulama tekniklerine olanak sağlamaktadır. Son yıllarda sulama alanında yapılan DSİ yatırımlarının neredeyse tamamı borulu sulama şebekeleridir. Borulu sulama şebekelerinin klasik kanal sistemlerinin yerini alması daha kontrollu bir şekilde tarımda sulama suyu kullanımının azalmasına neden olacaktır.

Borulu sulama şebekeleri ortalama olarak 6-8 ha (6-8 $\left.000 \mathrm{~m}^{2}\right)$ alana hizmet eden hidrantlar (su alma yapıları) ve suyu taşıyan borulardan oluşmaktadır. Avrupa ülkelerinde bir hidrantın ortalama servis alanı 13 ha iken Türkiye ortalaması 6.1 ha'dır [6]. Sulama şebekesi maliyetlerini düşürecek önemli bir çalışma da arazi toplulaştırma çalışmalarıdır. Çok mülkiyetli, parçalı arazilerdense düzenli araziler tarım verimliliğini arttırmakta ve sulama şebekeleri maliyetlerini düşürmektedir. Hidrantlara damlama ve yağmurlama sistemleri bağlanarak bitkilere sulama suyu ulaştırılmaktadır. Bu sistemlerin çalışabilmesi için hidrantlarda minimum $25 \mathrm{~m}$ su basıncı bulunmalıdır. Bu makalede sunulan çalışma sulama sisteminin hidrantlara kadar olan kısmını kapsamaktadır.

Devlet Su İşleri (DSİ) 'nin idari yapılanmasında toplamda 26 Bölgesi bulunmakta ve her bölgesinde de sulama projeleri tasarımları yapılmakta ve kontrol edilmektedir[8]. Farklı 
sulama projeleri için yapılan çalışmada sulama şebekeleri maliyetlerinin \%60'ını boru ile kazısının ve dolgusunun oluşturduğu tespit edilmiştir. Tablo 1 ve Şekil 1'de görüldüğü üzere, toplam sulama alanı arttıkça boru maliyetinin oranı da artmaktadır. Sulama sistemi içinde sanat yapıları olarak adlandırılan yapıları, vantuz, tahliye ve hidrant gibi ek yardımcı yapılar oluşturmaktadır. Sanat yapılarının sayısı ve maliyetlerinin azaltılması, boru çapları büyüklüğüne ve sulama arazisinin kullanım durumuna bağlıdır. Borulu sulama şebekelerinde boru çaplarını belirlemek ve en ekonomik şebekeyi sağlamak bu çalışmanın ana amacıdır.

1987 yılında yapılan çalışmaya göre, borulu sulama şebekelerindeki karmaşıklıklar nedeniyle mevcut optimizasyon metodlarını kullanmak mümkün değildir [18].

Tablo 1. Borulu şebekelerde boru ve kazısı maliyet oranları

\begin{tabular}{|c|c|c|c|c|c|}
\hline Proje adı & $\begin{array}{l}\text { Brüt } \\
\text { Alan } \\
\text { (ha) }\end{array}$ & $\begin{array}{c}\text { Boru ve } \\
\text { kazısı bedeli } \\
\text { (TL) }\end{array}$ & $\begin{array}{c}\text { Boru } \\
\text { maliyeti/ } \\
\text { toplam } \\
\text { maliyet }(\%)\end{array}$ & $\begin{array}{c}\text { Sanat } \\
\text { yapıları } \\
\text { bedeli (TL) }\end{array}$ & $\begin{array}{c}\text { Sanat } \\
\text { yapılarının } \\
\text { maliyetinin } \\
\text { toplam } \\
\text { maliyete oranı } \\
(\%)\end{array}$ \\
\hline $\begin{array}{l}\text { Edirne-Keşan Bahçeköy } \\
\text {,Çamlıca-Ihlamurdere, } \\
\text { Yenimucahir-Gökyar } \\
\text { Göleti ve Sulaması }\end{array}$ & 284,8 & 937.357 & 62 & 569.585 & 38 \\
\hline $\begin{array}{l}\text { Isparta Yalvaç Çakırcal } \\
\text { Göleti ve Sulaması }\end{array}$ & 132,0 & 405.117 & 52 & 375.287 & 48 \\
\hline $\begin{array}{l}\text { Karaman-Ermenek } \\
\text { Sarıvadi Göleti ve } \\
\text { Sulaması }\end{array}$ & 16,0 & 41.339 & 36 & 75.007 & 64 \\
\hline $\begin{array}{l}\text { Tunceli Hozat Uzundal } \\
\text { Göleti ve Sulaması }\end{array}$ & 706,9 & 7.875 .318 & 78 & 2.230 .471 & 22 \\
\hline $\begin{array}{l}\text { Bingöl Merkez Göltepesi } \\
\text { Göleti ve Sulaması }\end{array}$ & 325,0 & 1.709 .711 & 65 & 923.042 & 35 \\
\hline $\begin{array}{l}\text { Elazı̆̆ Karakoçan } \\
\text { Bazlama Göleti ve } \\
\text { Sulaması }\end{array}$ & 224,0 & 1.418 .897 & 65 & 771.681 & 35 \\
\hline $\begin{array}{l}\text { Karaman-Ermenek } \\
\text { Kazancı Göleti ve } \\
\text { Sulaması }\end{array}$ & 42,0 & 206.241 & 53 & 183.818 & 47 \\
\hline $\begin{array}{l}\text { Konya Hüyük Göçeri } \\
\text { Göleti ve Sulaması }\end{array}$ & 20,0 & 38.085 & 48 & 41.506 & 52 \\
\hline $\begin{array}{l}\text { Konya Hüyük Mutlu } \\
\text { Göleti ve Sulaması }\end{array}$ & 94,4 & 274.665 & 71 & 109.874 & 29 \\
\hline $\begin{array}{l}\text { Konya Hüyük Burunsuz } \\
\text { Göleti ve Sulaması }\end{array}$ & 37,0 & 109.641 & 68 & 50.508 & 32 \\
\hline & & Ortalama & 60 & & 40 \\
\hline
\end{tabular}




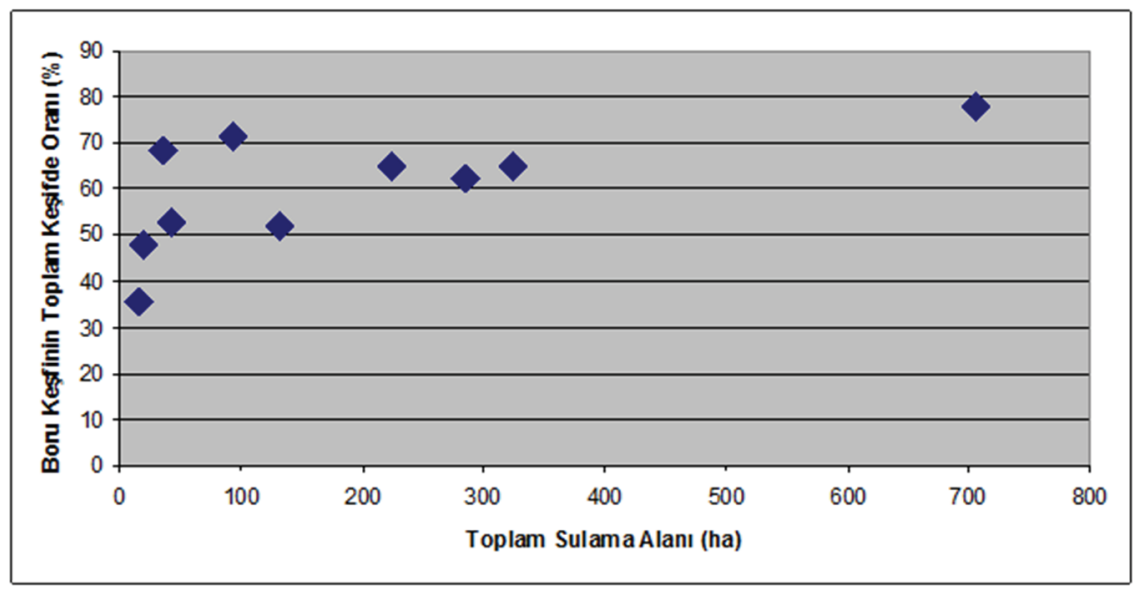

Şekil 1. Sulama alanı ile şebeke maliyeti iliş̧kisi

Sulama şebekeleri tasarımında sıklıkla karşılaşılan problemler: (1) sulama sistemini oluşturan pompa, vana, boru gibi elemanların farklı özelliklerde olması, (2) problemin doğrusal olmayan ve bazen bir değere yakınsamaz olma özellikleri nedeniyle ulaşılan sonuçların güvenilir olmaması ve (3) orta büyüklükte bir şebeke için bile yüksek bilgisayar hafızasına ve uzun çözüm zamanına ihtiyaç duyulmasıdır [9]. Bu makalede anılan bu sorunların aşılmasına yönelik çalışma yapılmıştır.

Optimizasyon algoritmalarında ana çözüm metodları; doğrusal programlama, doğrusal olmayan optimizasyon metodları, Labye metodu, dinamik programlama metodlarıdır [13]. Theocharis ve arkadaşları [17] geliştirdikleri doğrusal optimizasyon programlama metodu ile Labye optimizasyon metodunu karşılaştırmış ve iki metodun sonuçları arasında \% 1 civarında fark bulmuştur. Bu metodlardaki problem kısıtları boru uzunluğu ve piezometrik düşülerdir. Boru sayısının artmasıyla problemin karmaşıklığı artmaktadır. Dinamik programlama ve basitleştirilmiş doğrusal olmayan optimizasyon metodu karşılaştırılmış ve iki metodun da aynı sonuçlar verdiği tespit edilmiştir [17]. Dinamik metodun dezavantajı şebekenin boyutu büyüdüğü zaman, prosedürler daha karmaşık hale gelmekte ve şebeke çözüm süreleri uzamaktadır. Örneğin dört farklı boru çapı arasından seçim yapılan on borudan oluşan şebeke için 1.048.576 $\left(4^{10}\right)$ sayıda deneme yapılmalıdır. Diğer taraftan basitleştirilmiş doğrusal olmayan metod çok kolay ve pratiktir. Bahsedilen çalışmalarda [2] debi, boru boyutları ve pompa istasyonu enerji harcamaları optimize edilmeye çalışılmıştır. Tasarım debilerinin optimizasyonu Clement Metodu [3] kullanılarak yapılmıştır. Bu optimizasyon tekniği Türkiye'de 30 yıldır kullanılmaktadır. Devlet Su İşleri Genel Müdürlüğü için 1980 yılında Fransız BRL-GERSAR firması tarafindan oluşturulmuş olan "Network Optimizasyonu" programı halen sulama debisi hesabında bu metodu kullanmaktadır.

Network optimizasyon çalışmalarında doğrusal programlama ile integer programlama metodları da karşılaştırılmış, iki yöntemin de optimum sonuçlar verdiği tespit edilmiştir [14]. Debi ve enerji ilişkisi, doğrusal olmayan dışbükey maliyet şebeke akımı problemi çözümü 
ile araştırılmış ve kullanılan üç farklı algoritma Newton-Raphson tekniği ile karşılaştırılarak doğrusal olmayan dişbükey maliyet şebeke akımı problemi çözümünün optimum çözümden uzaklaştığ 1 tespit edilmiştir [4].

Çok amaçlı iki hybrid algoritması; ParEGO [12] ve LEMMO [11] algoritmaları test edilmiştir ve bu testler sonucunda LEMMO [11] algoritmasının karmaşık şebekelerde daha iyi sonuç verdiği, ParEGO [12] yönteminin karmaşıklığın az olduğu şebekelerde başarılı sonuçlar verdiği tespit edilmiştir [15]. Araştırmacılar [2], doğrusal olmayan programlama modelinde Excel tabanlı Solver programı ile hesaplanan boru çapları kullanarak şebekedeki her boru için gerekli debiyi Clement Metoduyla belirlemiştir.

GLOBE (küresel optimizasyon aracı) yazılımı ve EPANET [16] yazılımı arasında oluşturulan arayüz kullanılarak yapılan optimizasyon çalışması ile şebeke çözümleri gerçekleştirilmiştir [1]. Bu çalışmada akımın sürekliliği ve enerji kotu kıstaslarıyla doğrusal olmayan bir maliyet fonksiyonu bulunmuştur [1]. Örnek test problemleri çözümü için optimizasyon yazılımı olarak üst-sezgisel (meta-heuristic) algoritmalar içeren "GLOBE" yazılımı kullanılmıştır. Şebeke çözümü ise "EPANET" simülasyon yazılımı ile gerçekleştirilmiştir. Çalışmalarda doğrusal ve doğrusal olmayan metodlar karşılaştırılarak; bazılarının sonuçlarının uygun olmadığı, bazılarının ise pratik olmadıkları tespit edilmiştir [1].

\section{YÖNTEM}

Literatür çalışmalarında en uygun optimizasyon tekniği bulunmaya çalışılmıştır. En uygun optimizasyon çalışması seçimi için çözüm süresi, algoritma performansı ve sonuçlar değerlendirilmiştir. Bu çalışmada DSİ tarafından kabul edilmiş ve halen kullanılan "Network Optimizasyonu" yazılımı sonuçları ile çalışma kapsamında geliştirilen optimizasyon algoritma sonuçları karşılaştırılmıştır. $\mathrm{Bu}$ amaçla, doğrusal programlama tekniği olan heuristik tabanlı dinamik programlama ve simplex yöntemi kullanılmıştır. 1986 yılında Fransız bir firma tarafından üretilen ve bugüne kadar DSİ tarafından güvenle kullanılmış olan "Network Optimizasyonu" yazılımı referans alınmış ve çalışmada geliştirilen yazılımların sonuçları ile karşılaştırılmıştır.

\subsection{Borulu Sulama Sistemleri Optimizasyonu - Simplex Yöntemi}

Simplex yöntemi en hızlı çözüm veren doğrusal programlama yöntemi olarak tanımlanmaktadır, [2]. Sulama şebekesindeki boruların maliyetinin optimizasyonu, istenen şebeke basınçlarının sağlanarak belirlenen şebeke uzunluğuna göre boru çapları optimize edilerek sağlanır. Şebeke boru maliyetlerini etkileyen değişkenler şebeke uzunluğu, boru çapları ve şebeke hidrolik yük kayıplarıdır. Boru çapları boru cinslerine göre belirli çaplarda liste halinde olan değerlerdir. Şebekede istenen basıncı sağlayan en düşük maliyet, Denklem (1)'de verildiği gibi maliyet fonksiyonunun en düşük değeri ile sağlanabilir. Amaç fonksiyonu Denklem (1)'deki gibidir.

$\operatorname{Min} f(x)=C X$ 
Burada $\mathrm{C}$, birim metrede maliyet vektörü ve $\mathrm{X}$ ise boruların uzunluk vektörüdür. Problem kısıtları, özel fonksiyonel ve negatif olmayan kısıtlardır. İşletme açısından fonksiyonel kısıtlar, boru uzunluğu ve hidrolik kayıplardır. Denklem (2)'de verilen kısıt tüm boru uzunluklarının sıfırdan büyük olmasıdır.

Borulu sulama şebeke optimizasyonu problemi simplex algoritması kısıtları aşağıdaki gibi ifade edilebilir. Dal şebekedeki toplam boru uzunluğu sabittir ve girdi olarak algoritmaya tanitilir.

$\sum_{j=1}^{n} L_{i j}=L_{i}$

$\mathrm{L}_{\mathrm{i}}$ : i nolu borunun toplam uzunluğ, $\mathrm{L}_{\mathrm{ij}}=\mathrm{i}$ nolu borunun $\mathrm{j}$ nolu elemanı

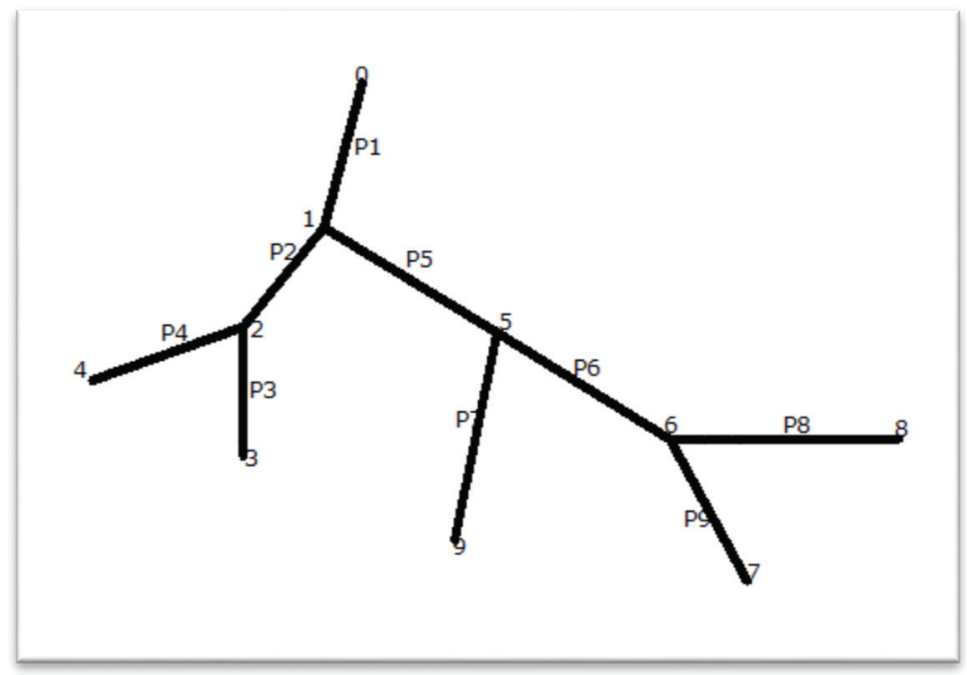

\begin{tabular}{|c|cccccccccc|}
\hline \multicolumn{1}{c}{1} & 0 & 1 & 2 & 3 & 4 & 5 & 6 & 7 & 8 & 9 \\
\cline { 2 - 12 } & -1 & 1 & 1 & 0 & 0 & 1 & 0 & 0 & 0 & 0 \\
3 & 0 & -1 & 1 & 0 & 0 & 9 & 0 & 0 & 0 & 0 \\
4 & 0 & 0 & -1 & 1 & 0 & 0 & 0 & 0 & 0 & 0 \\
5 & 0 & 0 & -1 & 0 & 1 & 0 & 0 & 0 & 0 & 0 \\
6 & 0 & -1 & 0 & 0 & 0 & 0 & 1 & 0 & 0 & 0 \\
7 & 0 & 0 & 0 & 0 & 0 & -1 & 1 & 0 & 0 & 0 \\
8 & 0 & 0 & 0 & 0 & 0 & -1 & $<9$ & 0 & 0 & 1 \\
9 & 0 & 0 & 0 & 0 & 0 & 0 & -1 & 0 & 1 & 0 \\
\hline & 0 & 0 & 0 & 0 & 0 & 0 & -1 & 1 & 0 & 0 \\
\hline
\end{tabular}

Şekil 2.Borulu şebeke için yol matrisi (Oklar "0" noktasından” 7” noktasına yolu tanımlamaktadır. 
Problem kısıtı, şebekenin amaç fonksiyonunu minimum yaparken Denklem (3)'teki eşitsizliği sağlayabilmektedir. Şebekedeki her hidrantta istenen basınç, her boru segmentindeki hidrolik kayıp hesaplanıp şebeke planındaki dal sistemine göre başlangıç basıncından düşülerek bulunacaktır. Şebeke planı da belirli bir algoritma ile optimizasyon algoritmasına tanıtılacaktır. Şebeke planının tanıtılması yol matrisi, $\mathrm{W}_{\mathrm{ij}}$, ile sağlanacaktır. Denklem (3)'teki eşitsizliğin yol matrisi ile dönüşen son hali 4. denklemdir. (3) ve (4) nolu denklemlerdeki 25 terimi yüksek basınçlı sulamada sağlanması gereken metre su sütunu cinsinden minimum basınç yüksekliğidir.

$E_{0}-\sum_{J=1}^{n} L_{i j} H_{i j}>\sum_{J=1}^{n} A_{j}+25$

$\mathrm{A}_{\mathrm{j}}$ : Arazi kotu (m)

$\mathrm{E}_{0}$ : Şebeke başlangıç noktası basıncı (m)

$\Delta \mathrm{H}$ : Hidrolik kayıp (m)

$E_{0}-\sum_{j=1}^{n} A_{J}+25>\sum_{j=1}^{n} L W_{i j} \Delta H \times W_{i j}$

Şebeke hidrolik kaybını ifade eden yol matrisi $W_{i j}$ (örneğin 9 boru için) Şekil 2'de verilmiştir. Burada 9. boru 6 ve 7 noktaları arasında bulunmaktadır. Matristeki ifadesi 1'den -1'e gitmektedir. 6. satıra gelindiğinde 6 . boru 5. noktadan 6 . noktaya olacak şekilde matrise tanımlanmıştır. Şekil 2'de her sırada birer tane -1ve 1 sayıları mevcutken birinci sırada birden fazla 1 sayısının olmasının sebebi iki ana kolun 1. noktada birleşmesidir. Böylelikle 9 borulu tüm şebeke matrise girilerek şebeke planı tanımlanmıştır. Tüm sulama şebekeleri planı yol matrisi ile algoritmaya tanıtılmaktadır.

\subsection{Debi ve Talep Hesapları}

Sulama sistemi toplam debisi talep yöntemi üzerinden hesaplanmaktadır. Bu yöntem sulama alanındaki her hidrant noktasında sürekli su sağlanmadığı ilkesine dayanmaktadır. Tüm hidrantların her zaman aynı anda açık olmadığı kabul edilmektedir. Bu yönteme göre şebekedeki ana ve yan kollardaki debiler, şebekenin her noktasında ulaşılabilir olduğu ilkesi kullanılarak istatiksel yöntemle hesaplanmaktadır. Şebekedeki tüm hidrantların aynı anda açık olmadığı kabul edilerek tüm hidrantların su ihtiyacı ayrı ayrı toplanarak bulunan debi miktarı aşağıda verilen Denklemler 9a, 9b ve 9c kullanılarak düşürülmektedir. Aksi takdirde her bir hidranttaki debi miktarının hidrant sayısı ile çarpılması sonucu elde edilen toplam debi miktarı çok yüksek çıkmaktadır. Bu durum boru çaplarını arttırdığı için ekonomik olmamaktadır. Bu nedenle debi değeri düşürülerek boru çaplarının ekonomik ve hidrolik açıdan uygun tasarlanması mümkün olmaktadır.

$Q_{t}=n q$

Burada n aynı anda çalışan hidrant sayısı, q ise aynı anda çalışan hidrantların birinden çekilen debi miktarıdır. Diğer taraftan sulama alanı A'ya sürekli sağlanan debi ise aşağıda verilen denklemle hesaplanır. 
$Q_{c}=A q_{\max }$

Burada $\mathrm{q}_{\max }$, A alanındaki ürün desenine ve aya göre hesaplanan sulama modülüdür (1/s/ha). Maksimum debinin 24 saat boyunca sürekli verilmesi pratik olarak mümkün olamayacağından, $\mathrm{Q}_{\mathrm{t}}>\mathrm{Q}_{\mathrm{c}}$ veya $\mathrm{nq}>\mathrm{Aq}_{\max }$ kabulü yapılarak periyodik olarak alana maksimum debi düzenli olarak verilir. $\mathrm{Bu}$ eşitsizlik ifadesinin sağ tarafı fleksibilite katsayısı olarak adlandırılan boyutsuz $\mathrm{F}$ parametresi ile çarpılarak nq=AFqmax eşitliğine dönüştürülür [7]. Sulama sistemi ister klasik veya borulu şebeke olsun debi denklemi aşağıdaki gibi yazılabilir:

$Q=n q=A F q_{\max }$

ve fleksibilite katsayısı aşağıdaki gibi ifade edilebilir:

$F=\frac{n q}{A q_{\max }}$

Burada n, aynı anda açık hidrant veya priz sayısı (klasik sistem için), q aynı anda açık olan hidrantların her birinin debisi (1/s), A sulama alanı (ha), F fleksibilite katsayısı olup, 1'den büyüktür. Fleksibilite katsayısı sulama alanının artmasıyla 1'e yaklaşır. Klasik sulama şebekeleri için Denklem (8)'le tanımlanan fleksibilite katsayısı, borulu şebeke için aşağıda verilen Denklem (9a) ile ifade edilebilir, [19].

$$
\begin{aligned}
& F=H\left(1+U \sqrt{\frac{1}{H}-\frac{1}{N}}\right) \\
& H=\frac{E \cdot q}{r \cdot d} \sum S_{e} \\
& r=\dot{T} / T \\
& N=Q_{i} / q
\end{aligned}
$$

Burada $U$, Normal dağılım eğrisinde $\% 95$ çalışma olasılı̆̆ına denk gelen sayıdır. Örneğin $\operatorname{Prob}(\mathrm{U})=0.05$ ise $U=1.645$ tir. $T$ bir günlük toplam süre ve 24 saate eşittir, $T^{\prime}$ sulama süresi, $E$ net sulama alanının brüt sulama alanına oranı (Net alan/Brüt Alan), $q$ teorik parsel için ortalama gerekli debi, ve $S_{e}$ brüt alan, $H$ ortalama kapasitede aynı anda çalışan hidrant sayısı $Q_{i}$ hattın toplam debisi ve $N$ toplam hidrant sayısidır.

Tablo 2'de örnek bir sulama alanında Denklemler (9a, 9b ve 9c) kullanılarak sulama debisinin nasıl azaltıldığ 1 gösterilmiştir. Bu tabloda sulama modülü $0.40 \mathrm{lt} / \mathrm{s} / \mathrm{ha}$ olan ve üzerinde ortalama 218 adet hidrant bulunan 1742 ha brüt sulama alanında toplam sulama debisi 868 lt/s bulunmuştur. Örnek problemde görüldüğü üzere 218 adet hidrantın aynı anda açık olması durumunda ve her bir hidrantın 8 ha alanı 10 lt/s lik debiyle sulaması sonucunda $2180 \mathrm{lt} / \mathrm{s}$ sulama debisine ihtiyaç vardır. Uygulanan istatiksel yöntem ile toplam maksimum debi miktarı 868 lt/s'ye düşürülmüştür. Bu metot her borunun mansabındaki sulama alanı için hesaplanmakta böylelikle her boru için ayrı ayrı tasarım debisi bulunmaktadır. 
Tablo 2. Borulu sulama şebekesi örnek debi hesabı

\begin{tabular}{||c|l|l|l||}
\hline \hline Simge & Veriler & Birim & Açıklamalar \\
\hline $\mathrm{q}_{\max }$ & 0,40 & $1 \mathrm{t} / \mathrm{s} / \mathrm{ha}$ & sulama modülü \\
\hline $\mathrm{U}$ & 1,645 & & Gauss ihtimal katsayıs $(\mathrm{U}=1.645)$ \\
\hline $\mathrm{E}$ & 0,9 & & net alan /brüt alan \\
\hline $\mathrm{T}^{\prime}$ & 20 & saat & sulama zamanı \\
\hline $\mathrm{T}$ & 24 & saat & \\
\hline $\mathrm{r}$ & 0,833 & & \\
\hline $\mathrm{q}$ & 10 & $1 \mathrm{t} / \mathrm{s} / 8 \mathrm{ha}$ & teorik hidrant alanı debisi \\
\hline$\Sigma \mathrm{Se}$ & 1742 & ha & brüt alan \\
\hline & 1567 & ha & net alan \\
\hline $\mathrm{N}$ & 218 & & toplam hidrant sayıs1 \\
\hline $\mathrm{H}$ & 75,3 & & aynı zamanda çalışan hidrant say1S1 \\
\hline $\mathrm{F}$ & 86,8 & & fleksibilite say1s1 \\
\hline $\mathrm{Q}$ & 868 & lt/s & toplam debi \\
\hline
\end{tabular}

\subsection{Hidrolik Kayıp Hesapları}

Türkiye'deki borulu sulama şebekelerinde hidrolik kayıplar Colebrook denklemi kullanılarak hesaplanır. DSİ tarafindan kullanılan yazılımda da aynı denklem kullanılmaktadır. Colebrook bilindiği üzere deneme yanılma yapılarak kullanılan bir denklemdir. Denklem (10) da verilen hali DSİ Network programında kullanılan, basitleştirilmiş, tek bilinmeyenli denklem halidir. Bu çalışmada geliştirilen optimizasyon metodu, DSİ Network metodu ile karşılaştırıldığı için aynı kayıp denklemi kullanılmıştır.

$J=\frac{L Q^{M} D^{-N}}{100}$

Burada $J$, hidrolik eğim $(\mathrm{m} / \mathrm{m}), Q$, debi $\left(\mathrm{m}^{3} / \mathrm{s}\right), D$, boru çap1 $(\mathrm{m}), L, M, N$ parametreleri $K$ pürüzlülük katsayısına bağlı olarak verilmektedir, [20]. DSİ uygulamalarında güvenli tarafta kalmak için PE ve CTP tipi boru kullanılmasına rağmen kayıp hesaplarında $\mathrm{K}=0.5$ (beton borular için kullanılan katsayı ) kullanılmaktadır. İleride oluşabilecek yeni sulama alanı taleplerini karşılayabilmek, boruların zamanla aşınmasından dolayı güvenli tarafta kalmak için hidrolik kayıplar olduğundan daha yüksek hesaplanmaktadır.

\subsection{Heuristik Tabanlı Dinamik Modelleme Algoritması Sonuçları ve DSİ Network Programı İle Karşılaştırılması}

Heuristik tabanlı dinamik modellemede boru çapı için hız sınırlarına göre belirlenen farklı boru çapı arasından seçim yapılmaktadır. Hidrantlarda minimum basınç yüksekliği koşulunu sağlayan hat debileri için hız limitlerine göre olası boru çapları hesaplanmaktadır. Algoritma hesaplamaları ile olası boru çapları arasından seçim yapılmaktadır. Heuristik tabanlı dinamik modelleme algoritmasında debi hesabı ve boru kayıları için kullanılan hesap yöntemi, simplex algoritmasında ve DSİ Network yazılımında kullanılan yöntem ile aynıdır. 
Algoritma, Excel programının arka planındaki visual basic kullanılarak yapılmıştır. DSİ Network programı sonuçları ile heuristik tabanlı dinamik modelleme sonuçları karşılaştırıldığında \%99 oranda benzerlik tespit edilmiştir, (Tablo 3). On farklı şebeke için karşılaştırma yapılmıştır. DSİ'nin kullandığı Network programı ile kullanılan algoritma sonuçları karşılaştırıldığında en fazla fark \%1.441 ile İvrindi Projesi şebekesi sonuçlarında görülmüştür, (Tablo 3).

Tablo 3 . Heuristik tabanlı dinamik algoritma ile DSİ Network yazılımı sonuçları karşılaştırması

\begin{tabular}{||l|c|l|l|c|c|c|l||}
\hline \multicolumn{1}{|c|}{$\begin{array}{c}\text { Proje } \\
\text { Ad1 }\end{array}$} & $\begin{array}{c}\text { Toplam } \\
\text { Sulama } \\
\text { Alan1 } \\
(\text { ha) }\end{array}$ & $\begin{array}{c}\text { Toplam } \\
\text { Debi } \\
(\mathrm{l} / \mathrm{s})\end{array}$ & $\begin{array}{c}\text { Toplam } \\
\text { Düğ̈m } \\
\text { Say1s1 }\end{array}$ & $\begin{array}{c}\text { DSI } \\
\text { Network } \\
\text { Maliyeti } \\
(\mathrm{TL})\end{array}$ & $\begin{array}{c}\text { Heuristik } \\
\text { Algoritma } \\
\text { Maliyeti } \\
(\mathrm{TL})\end{array}$ & $\begin{array}{c}\text { Heuristik } \\
\text { Maliyet } \\
\text { Fark1 } \\
(\mathrm{TL})\end{array}$ & $\begin{array}{c}\text { Heuristik } \\
\text { Hata Oran1 } \\
\%\end{array}$ \\
\hline İvrindi & 174,6 & 215 & 37 & 512899 & 520289 & 7390 & 1,441 \\
\hline Çamlı & 66,1 & 66 & 41 & 121187 & 121187 & 0 & 0 \\
\hline Sapkanl1 & 254,9 & 278 & 72 & 1158316 & 1163489 & 5173 & 0,447 \\
\hline Kay1 & 342,2 & 239 & 96 & 862222 & 863507 & 1285 & 0,149 \\
\hline Çatköy & 727 & 561 & 117 & 3289830 & 3298849 & 9019 & 0,274 \\
\hline Beyköy & 502,3 & 393 & 125 & 920512 & 921543 & 1031 & 0,112 \\
\hline Yaylabelen & 451,7 & 352 & 147 & 1445082 & 1445082 & 0 & 0 \\
\hline Ayvalı & 1609,5 & 1552 & 179 & 6002618 & 6019631 & 17013 & 0,283 \\
\hline Güney & 482,5 & 373 & 219 & 1109347 & 1109347 & 0 & 0 \\
\hline Bulanık & 6402 & 8894 & 1362 & 68101353 & 68283697 & 182344 & 0,268 \\
\hline
\end{tabular}

Tablo 4. Heuristik tabanlı dinamik algoritma ile DSİ Network yazılımı sonuçlarının süre açısından karşılaştırılması

\begin{tabular}{||c|c|c|c|c|c||}
\hline $\begin{array}{c}\text { Proje } \\
\text { Ad1 }\end{array}$ & $\begin{array}{l}\text { Toplam } \\
\text { Sulama } \\
\text { Alan1 (ha) }\end{array}$ & $\begin{array}{c}\text { Toplam } \\
\text { Debi (1/s) }\end{array}$ & $\begin{array}{c}\text { Düğ̈̈m } \\
\text { Say1s1 }\end{array}$ & $\begin{array}{c}\text { Heuristik } \\
\text { Algoritmas1 } \\
\text { Maliyeti (TL) }\end{array}$ & $\begin{array}{c}\text { Heuristik } \\
\text { Çözüm Süresi } \\
\text { (s) }\end{array}$ \\
\hline İvrindi & 174,6 & 215 & 37 & 520289 & 0,24 \\
\hline Çaml1 & 66,1 & 66 & 41 & 121187 & 0,26 \\
\hline Sapkanl1 & 254,9 & 278 & 72 & 1163489 & 0,51 \\
\hline Kay1 & 342,2 & 239 & 96 & 863507 & 0,51 \\
\hline Çatköy & 727 & 561 & 117 & 3298849 & 1,18 \\
\hline Beyköy & 502,3 & 393 & 125 & 921543 & 0,64 \\
\hline Yaylabelen & 451,7 & 352 & 147 & 1445082 & 0,76 \\
\hline Ayval1 & 1609,5 & 1552 & 179 & 6019631 & 1,06 \\
\hline Güney & 482,5 & 373 & 219 & 1109347 & 1,14 \\
\hline Bulanık & 6402 & 8894 & 1362 & 68283697 & 123,43 \\
\hline
\end{tabular}




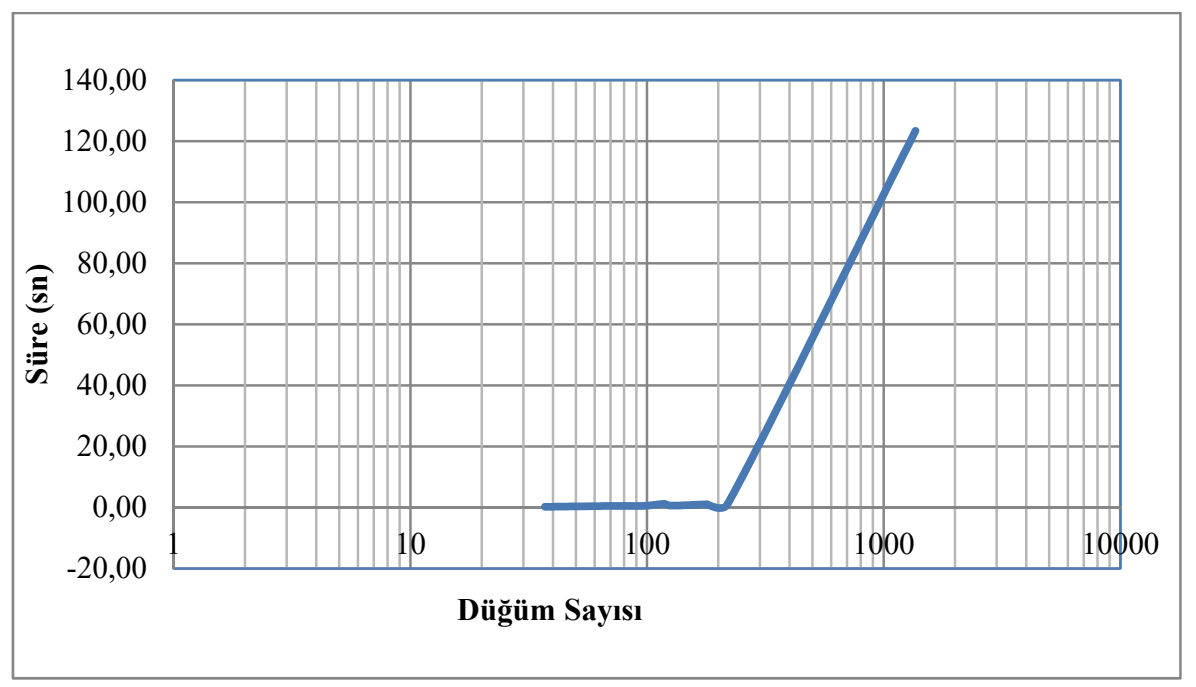

Şekil 3. Şebeke düğüm saylsı \& çözüm süresi grafiği

Sonuçlar değerlendirildiğinde, bu çalışmada geliştirilen Heuristik algoritma ile DSİ'nin kullandığı yazılım arasında maliyetler açısından Tablo 3’te görüldüğü gibi önemsenecek bir fark bulunmadığı görülmüştür. Ancak Heuristik algoritma performans açısından değerlendirildiğinde Tablo 4‘te görüldüğü üzere şebeke alanı büyüdükçe çözüm süresi uzamaktadır. Bulanık sulaması (6402 ha) Tablo 4'te görüldüğ̈̈ üzere 123 saniye sürmektedir. Şekil 3'de görüldüğü üzere düğüm sayısı yaklaşık olarak 200'ü geçtiğinde çözüm süresi doğrusal bir şekilde artmaktadır. Algoritmanın çözüm süresi performansını arttırmak amaçlı ikinci bir algoritma olarak "Simplex" yöntemi kullanılmıştır.

\subsection{Simplex Yöntemi Algoritması Sonuçları ve DSİ Network Programı ile Karşılaştırılması}

Simplex algoritması kullanılarak yapılan çalışmalar analiz edildiğinde, DSİ Network programı ile aynı sonuçları 1-2 saniye gibi kısa sürede verdiği görülmüştür. Simplex algoritması kullanılarak elde edilen sonuçlar, DSI Network yazılımı sonuçları ile karşılaştırılmıştır. Tablo 5'te görüldüğü üzere on sulama projesinin sekizinin maliyetleri aynı olup; iki tanesinin ise geliştirilen Simplex yazılımı sonuçları daha ekonomiktir. DSİ Network yazılımı ile bu çalışmada geliştirilen Simplex yazılımı algoritmasının çok benzer olduğu tahmin edilmektedir. 
Tablo 5. Geliştirilen Network yazılımının sonuçları ile DSİ Network yazılımı sonuçlarının karşılaştırılması

\begin{tabular}{||l|c|c|c|c|c|c||}
\hline $\begin{array}{c}\text { Proje } \\
\text { Adı }\end{array}$ & $\begin{array}{l}\text { Toplam } \\
\text { Sulama } \\
\text { Alanı }\end{array}$ & $\begin{array}{c}\text { Toplam } \\
\text { Debi }\end{array}$ & $\begin{array}{c}\text { Toplam } \\
\text { Düğüm } \\
\text { Sayısı }\end{array}$ & $\begin{array}{c}\text { DSI } \\
\text { Network } \\
\text { Maliyeti }\end{array}$ & $\begin{array}{c}\text { Yeni } \\
\text { Yazılım } \\
\text { (Simplex) } \\
\text { Maliyeti }\end{array}$ & $\begin{array}{c}\text { Yeni Yazılım } \\
\text { (Simplex) } \\
\text { Çözüm Süresi } \\
\text { (sn) }\end{array}$ \\
\hline İvrindi & 174,60 & 215 & 37 & 512899 & 512899 & 0,0156 \\
\hline Çamlı & 66,10 & 66 & 41 & 121187 & 121187 & 0,0000 \\
\hline Sapkanlı & 254,90 & 278 & 72 & 1158316 & 1154435 & 0,0312 \\
\hline Kayı & 342,20 & 239 & 96 & 862222 & 862222 & 0,0156 \\
\hline Çatköy & 727,00 & 561 & 117 & 3289830 & 3289830 & 0,0312 \\
\hline Beyköy & 502,30 & 393 & 125 & 920512 & 920512 & 0,0312 \\
\hline Yaylabelen & 451,70 & 352 & 147 & 1445082 & 1445082 & 0,0156 \\
\hline Ayvalı & 1609,50 & 1552 & 179 & 6002618 & 6002619 & 0,0312 \\
\hline Güney & 482,50 & 373 & 219 & 1109347 & 1109347 & 0,0312 \\
\hline Bulanık & 6402,00 & 8894 & 1362 & 68101353 & 68093472 & 1,0608 \\
\hline \hline
\end{tabular}

\subsection{Beş Borulu Bir Şebeke için Simplex, DSİ Network ve Excel (Doğrusal Yöntem) Çözümlerinin Karşılaştırılması}

Beş ana borulu basit bir şebeke problemi; Excel, mevcut DSİ Network yazılımı ve bu çalışmada geliştirilen ve Simplex algoritmasını kullanan yazılımla çözülmüştür. Beş borulu şebeke teorik olarak oluşturulmuş gerçek olmayan bir şebekedir. Şebeke boruları üzerine içerisinden geçen debiler, boru uzunlukları ile bu debilere ve hız kriterlerine bağlı olası boru çapları yazılmıştır, (Şekil 4). Şebeke başlangıç kotu ve hidrant noktalarında istenen basınçlar da aynı şekilde gösterilmiştir. Böyle basit bir şebekenin DSİ Network, Excel ve bu çalışmada geliştirilen Simplex yöntemini kullanan algoritma ile çözümü yapılıp karşılaştırılmıştır.

\subsubsection{Excel Çözücü'de Beş Borulu Şebeke İçin Çözüm Örneği}

Karmaşık şebekelerin çözümü Excel'de oldukça zordur. Büyük bir şebeke için kayıp denkleminin yazılması oldukça zor olup; hata yapma olasılığı çok yüksektir. Excel makroları ile boru kayıp denklemleri yazılabilir ancak Excel'in satır sınırı büyük sulama şebekeleri çözümüne olanak vermemektedir. Ancak yine de algoritmayı test etmek için Excel programının "Çözücü” aracı kullanılarak oluşturulan çözüm ile DSİ Network yazılımı sonuçları karşılaştırılmıştır. Öncelikle hız sınırlarına göre olası boru çapları her boru için hesaplanmıştır, (Tablo 6). Tablo 6'da görüldüğü üzere hız kriterlerine göre hesaplanan olası boru çapları için birim hidrolik kayıplar hesaplanmıştır. Her bir boru için hidrolik kayıplar hesaplanmış ve Tablo 7'de verilmiştir. 


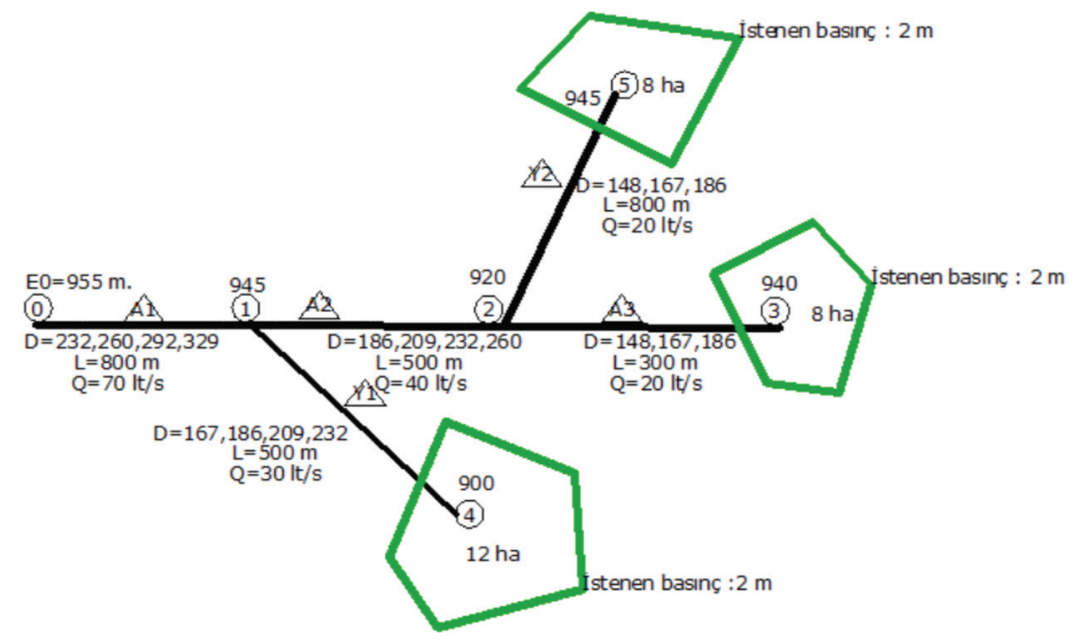

Şekil 4. Beş Borulu şebeke planı

Tablo 6. İç çaplar ve hız kriterleri

\begin{tabular}{|c|c|c|c|c|c|}
\hline $\begin{array}{l}\text { D iç çap } \\
(\mathrm{mm})\end{array}$ & $\begin{array}{l}V_{\min } \\
(\mathrm{m} / \mathrm{s})\end{array}$ & $\begin{array}{l}V_{\max } \\
(\mathrm{m} / \mathrm{s})\end{array}$ & $\begin{array}{c}\text { D iç çap } \\
(\mathrm{mm})\end{array}$ & $\begin{array}{l}V_{\min } \\
(\mathrm{m} / \mathrm{s})\end{array}$ & $\begin{array}{l}V_{\text {max }} \\
(\mathrm{m} / \mathrm{s}) \\
\end{array}$ \\
\hline 102 & 0,1 & 1,5 & 417 & 0,6 & 1,91 \\
\hline 116 & 0,6 & 1,5 & 464 & 0,6 & 1,95 \\
\hline 130 & 0,6 & 1,5 & 519 & 0,6 & 1,95 \\
\hline 148 & 0,6 & 1,5 & 600 & 0,6 & 2,3 \\
\hline 167 & 0,6 & 1,5 & 700 & 0,6 & 2,3 \\
\hline 186 & 0,6 & 1,55 & 800 & 0,6 & 2,5 \\
\hline 209 & 0,6 & 1,6 & 900 & 0,6 & 2,5 \\
\hline 232 & 0,6 & 1,65 & 1000 & 0,6 & 2,5 \\
\hline 260 & 0,6 & 1,65 & 1100 & 0,6 & 2,5 \\
\hline 292 & 0,6 & 1,7 & 1200 & 0,6 & 2,5 \\
\hline 329 & 0,6 & 1,7 & 1300 & 0,6 & 2,5 \\
\hline 371 & 0,6 & 1,77 & 1400 & 0,6 & 2,5 \\
\hline & & & 1500 & 0,6 & 2,5 \\
\hline
\end{tabular}


Tablo 7. Olası boru çapları ve hidrolik verileri

\begin{tabular}{|c|c|c|c|c|c|c|}
\hline & & $\begin{array}{c}\text { Debi } \\
\mathrm{Q}\left(\mathrm{m}^{3} / \mathrm{s}\right)\end{array}$ & $\begin{array}{c}\text { Boru } \\
\text { Çap1 } \\
\text { D (m) }\end{array}$ & $\begin{array}{c}\text { Kesit } \\
\text { Alanı }\left(\mathrm{m}^{2}\right)\end{array}$ & $\begin{array}{l}\text { Akım Hizı } \\
(\mathrm{m} / \mathrm{s})\end{array}$ & $\begin{array}{c}\text { Birim } \\
\text { uzunlukta } \\
\text { yük kayb1 } \\
\Delta \mathrm{H}(\mathrm{m} / \mathrm{m})\end{array}$ \\
\hline \multirow{4}{*}{ Boru 0} & L01 & 0,07 & 0,232 & 0,0423 & 1,656 & 0,0150 \\
\hline & L02 & 0,07 & 0,26 & 0,0531 & 1,318 & 0,0081 \\
\hline & L03 & 0,07 & 0,292 & 0,0670 & 1,045 & 0,0045 \\
\hline & L04 & 0,07 & 0,329 & 0,0850 & 0,823 & 0,0024 \\
\hline \multirow{4}{*}{ Boru 1} & L11 & 0,07 & 0,232 & 0,0423 & 1,656 & 0,0150 \\
\hline & L12 & 0,07 & 0,26 & 0,0531 & 1,318 & 0,0083 \\
\hline & L13 & 0,07 & 0,292 & 0,0670 & 1,045 & 0,0045 \\
\hline & L14 & 0,07 & 0,329 & 0,0850 & 0,823 & 0,0025 \\
\hline \multirow{4}{*}{ Boru 2} & L21 & 0,04 & 0,26 & 0,0531 & 0,753 & 0,0028 \\
\hline & L22 & 0,04 & 0,232 & 0,0423 & 0,946 & 0,0050 \\
\hline & L23 & 0,04 & 0,209 & 0,0343 & 1,166 & 0,0086 \\
\hline & L24 & 0,04 & 0,186 & 0,0272 & 1,472 & 0,0158 \\
\hline \multirow{3}{*}{ Boru 3} & L31 & 0,02 & 0,148 & 0,0172 & 1,163 & 0,0133 \\
\hline & L32 & 0,02 & 0,167 & 0,0219 & 0,913 & 0,0071 \\
\hline & L33 & 0,02 & 0,186 & 0,0272 & 0,736 & 0,0041 \\
\hline \multirow{4}{*}{ Boru 4} & L41 & 0,03 & 0,167 & 0,0219 & 1,370 & 0,0157 \\
\hline & L42 & 0,03 & 0,186 & 0,0272 & 1,104 & 0,0070 \\
\hline & L43 & 0,03 & 0,209 & 0,0343 & 0,874 & 0,0049 \\
\hline & L44 & 0,03 & 0,232 & 0,0423 & 0,710 & 0,0028 \\
\hline \multirow{3}{*}{ Boru 5} & L51 & 0,02 & 0,148 & 0,0172 & 1,163 & 0,0133 \\
\hline & L52 & 0,02 & 0,167 & 0,0219 & 0,913 & 0,0071 \\
\hline & L53 & 0,02 & 0,186 & 0,0272 & 0,736 & 0,0041 \\
\hline
\end{tabular}

Tablo 8.1. Beş borulu şeholo için Excel sonuçlart - Boru uzunluğu matrisi

\begin{tabular}{|c|c|c|c|c|c|c|c|c|c|c|}
\hline Boru uzunluğu sonuç: & 800 & ,27,1273 & 172,8727 & 300 & 500 & 800 & & Matris & Boru & Boru Kodu \\
\hline Boru Kodu: & L12 & 122 & $\mathrm{~L} 23$ & L31 & L41 & L53 & & sonucu & uzunluğu $(\mathrm{m})$ & \\
\hline \multirow{6}{*}{ Şebeke matrisi : } & 0 & 0 & 0 & 0 & 0 & 0 & $=$ & 0,1 & 0,1 & LO \\
\hline & 1 & 0 & 0 & 0 & 0 & 0 & $=$ & 800 & 800 & $\mathrm{~L} 1$ \\
\hline & 0 & 1 & 1 & 0 & 0 & 0 & $=$ & 500 & 500 & $\mathrm{~L} 2$ \\
\hline & 0 & 0 & 0 & 1 & 0 & 0 & $=$ & 300 & 300 & L3 \\
\hline & 0 & 0 & 0 & 0 & 1 & 0 & $=$ & 500 & 500 & L4 \\
\hline & 0 & 0 & 0 & 0 & 0 & 1 & $=$ & 800 & 800 & $\mathrm{~L} 5$ \\
\hline
\end{tabular}


Tablo 8.2. Beş borulu şebeke için Excel sonuçları - Kayıp matrisi

\begin{tabular}{|c|c|c|c|c|c|c|c|c|c|c|}
\hline Kayıр Kodu : & $\Delta \mathrm{H} 12$ & $\Delta \mathrm{H} 22$ & $\Delta \mathrm{H}_{2} 3$ & $\Delta \mathrm{H} 31$ & $\Delta \mathrm{H} 41$ & $\Delta \mathrm{H} 53$ & & \begin{tabular}{|l|} 
Matris \\
sonucu
\end{tabular} & $\begin{array}{l}\text { Eo- } \\
(\mathrm{A}+\text { Isstenen } \\
\end{array}$ & \begin{tabular}{|l|} 
A(Arazi \\
kotu)-m
\end{tabular} \\
\hline \multirow{6}{*}{ Hidrolik kayıp matrisi } & 0 & 0 & 0 & 0 & 0 & 0 & & 0,000829 & 5 & 955 \\
\hline & 0,008295 & 0 & 0 & 0 & 0 & 0 & $\leq=$ & 6,636709 & 13 & 945 \\
\hline & 0,008295 & 0,005004 & 0,008602 & 0 & 0 & 0 & $\leq$ & 9,7606 & 38 & 920 \\
\hline & 0,008295 & 0,005004 & 0,008602 & 0,013258 & 0 & 0 & $\leq=$ & 13,7381 & 18 & 940 \\
\hline & 0,008295 & 0 & 0 & 0 & 0,015681 & 0 & $\leq$ & 14,47745 & 58 & 900 \\
\hline & 0,008295 & 0,005004 & 0,008602 & 0 & 0 & 0,004049 & $<=$ & 13 & 13 & 945 \\
\hline Olası boru çapı (mm) : & 260 & 232 & 209 & 148 & 167 & 186 & & & Toplam bedel & 94612,3057 \\
\hline Boru bedeli $(\$ / \mathrm{m})$ : & 48,4 & 39,38 & 32,58 & 18,34 & 22,19 & 25,97 & & & & \\
\hline
\end{tabular}

Tablo 9. Beş borulu şebeke çözümü sonuçları özeti

\begin{tabular}{|c|c|c|c|c|c|c|c|}
\hline & $\begin{array}{c}\text { Boru } \\
\text { No }\end{array}$ & $\begin{array}{c}\text { Debi } \\
\mathrm{Q}\left(\mathrm{m}^{3} / \mathrm{s}\right)\end{array}$ & $\begin{array}{c}\text { Boru } \\
\text { Çap1 } \\
\text { D (m) }\end{array}$ & $\begin{array}{c}\text { Kesit } \\
\text { Alanı }\left(\mathrm{m}^{2}\right)\end{array}$ & $\begin{array}{l}\text { Akım hizı } \\
\text { V (m/s) }\end{array}$ & $\begin{array}{l}\text { Birim } \\
\text { Uzunlukta } \\
\text { yük kaybı } \\
\Delta \mathrm{H}(\mathrm{m} / \mathrm{m})\end{array}$ & $\mathbf{L}(\mathbf{m})$ \\
\hline \multirow{4}{*}{ Boru 0} & L01 & 0,07 & 0,232 & 0,0422733 & 1,6558927 & 0,0149843 & $\mathbf{0}$ \\
\hline & L02 & 0,07 & 0,26 & 0,0530929 & 1,3184433 & 0,0082948 & 0,1 \\
\hline & L03 & 0,07 & 0,292 & 0,0669662 & 1,0453036 & 0,0045413 & 0 \\
\hline & L04 & 0,07 & 0,329 & 0,0850123 & 0,8234104 & 0,002445 & $\mathbf{0}$ \\
\hline \multirow{4}{*}{ Boru 1} & L11 & 0,07 & 0,232 & 0,0422733 & 1,6558927 & 0,0149843 & $\mathbf{0}$ \\
\hline & L12 & 0,07 & 0,26 & 0,0530929 & 1,3184433 & 0,0082948 & 800 \\
\hline & L13 & 0,07 & 0,292 & 0,0669662 & 1,0453036 & 0,0045413 & $\mathbf{0}$ \\
\hline & L14 & 0,07 & 0,329 & 0,0850123 & 0,8234104 & 0,002445 & $\mathbf{0}$ \\
\hline \multirow{4}{*}{ Boru 2} & L21 & 0,04 & 0,26 & 0,0530929 & 0,7533962 & 0,0027698 & $\mathbf{0}$ \\
\hline & L22 & 0,04 & 0,232 & 0,0422733 & 0,9462244 & 0,0050036 & 327,1 \\
\hline & L23 & 0,04 & 0,209 & 0,034307 & 1,1659436 & 0,0086021 & 172,9 \\
\hline & L24 & 0,04 & 0,186 & 0,0271716 & 1,4721234 & 0,0157541 & 0 \\
\hline \multirow{3}{*}{ Boru 3} & L31 & 0,02 & 0,148 & 0,0172034 & 1,1625635 & 0,0132583 & 300 \\
\hline & L32 & 0,02 & 0,167 & 0,021904 & 0,9130765 & 0,0070835 & $\mathbf{0}$ \\
\hline & L33 & 0,02 & 0,186 & 0,0271716 & 0,7360617 & 0,0040493 & 0 \\
\hline \multirow{4}{*}{ Boru 4} & L41 & 0,03 & 0,167 & 0,021904 & 1,3696148 & 0,0156815 & 500 \\
\hline & L42 & 0,03 & 0,186 & 0,0271716 & 1,1040926 & 0,0089642 & $\mathbf{0}$ \\
\hline & L43 & 0,03 & 0,209 & 0,034307 & 0,8744577 & 0,0048947 & $\mathbf{0}$ \\
\hline & L44 & 0,03 & 0,232 & 0,0422733 & 0,7096683 & 0,0028471 & 0 \\
\hline \multirow{3}{*}{ Boru 5} & L51 & 0,02 & 0,148 & 0,0172034 & 1,1625635 & 0,0132583 & 0 \\
\hline & L52 & 0,02 & 0,167 & 0,021904 & 0,9130765 & 0,0070835 & 0 \\
\hline & L53 & 0,02 & 0,186 & 0,0271716 & 0,7360617 & 0,0040493 & 800 \\
\hline
\end{tabular}


Tüm şebeke boru uzunlukları için olası boruların çapları karşısına yazılmıştır. Maliyeti minimum tutacak istenen enerjileri sağlayacak olası boru çapları arasından seçim yapılmıştır. Excel'in "Çözücü” aracı ile maliyeti minimum yapacak istenen basınç yüksekliğini sağlayacak boru çapları bulunmuştur. Çözüm sonucunda görüldüğü üzere (Tablo 8.1 ve Tablo 9 ) 2. boru çap1 327. m'de değişmiş 232 mm’den 209 mm'ye düşmüştür. Çözüm sonucu ve 5 borulu şebeke bilgileri özet olarak Tablo 9'da verilmiştir.

\subsubsection{DSİ Network Programında Beş Borulu Şebeke İçin Çözüm Örneği}

1986 yılında Fransız BRL GERSAR firması tarafından geliştirilen DSİ genel müdürlüğünde 2 adet bilgisayarda yüklü olan "Network" yazılımı DOS ortamında çalışmaktadır. Firma temsilcilerine ulaşılamadığı ve yazılım algoritması hakkında bir bilgiye ulaşılamadığından optimizasyon denklemlerinde kullanılan algoritma bilinmemektedir. DSİ'nin 26 bölgesinde projelendirilen Türkiye'deki tüm sulama projeleri tasarımı bu yazılım ile üretilmektedir. Sulama projelerinin tasarımını yapan firmalar bu yazılımı kullanmak için DSİ Genel Müdürlüğüne çözüm alabilmek için gelmektedirler. Tasarım mühendisleri ve DSİ Bölge Müdürlüklerindeki kontrol teşkilatlarındaki kontrol mühendisleri için borulu sulama şebekelerini çözen bu yazılıma ulaşım pek kolay olmamaktadır. Bu nedenle yapılan hesaplarda hata yapma olasılığı artmaktadır.

Yazılımın girdi dosyası "Data" ve "Gen" uzantılı text dosyalarıdır. Data uzantılı dosyada şebekenin geometrisi, boru adları, boru uzunlukları, hidrant yerleri ve arazi kotları bilgileri bulunmaktadır. Gen uzantılı dosya olası tüm boru maliyetleri, hız limitleri, sulama modülü gibi şebeke hidrolik çözümü için gerekli bilgileri içermektedir. Data uzantılı dosyada maksimum satır sayısı limiti 1400'dür. 5 borulu sulama şebekesi için yapılan çözüm ve sonucu Ek 1'de sunulmuştur. 2. Borudaki redüksiyon boru değişim noktası excel çözümü ile aynıdır.

\subsubsection{Simplex Tabanlı Algoritma ile Beş Borulu Şebekenin Çözümü}

Bu çalışmada geliştirilen Simplex tabanlı yazılım 2016 yılında DSİ Genel Müdürlüğü ile yapılan protokol ile DSİ Genel Müdürlüğü ve Bölge Müdürlükleri tarafindan kullanılabilmektedir. Ayrıca tasarım firmaları tarafından da kullanılabilmektedir. Yazılımın beş adet ara yüzü bulunmaktadır. Bu ara yüzlerden sulama şebekesi bilgileri alınmaktadır. Beş borulu şebeke için bu çalışmada geliştirilen Network yazılımı sonuçları Excel ve DSI Network programlarında bulunan sonuçlarla birebir uyumludur (Tablo 10). İkinci borudaki redüksiyon yerleri dahi tüm sonuçlarda aynıdır. Tablo 10 'da görüldüğü üzere her borunun uzunluğu başlangıç ve bitiş kotu ile verilmiştir. Boru çapı değişim noktaları boru uzunluğu vb özelliklerin değiştiği yerler Tablo 10'un satırında 1 ve 2 sayıları ile ifade edilmiştir. Tablo 10 'da görüldüğü gibi 2. boru için boru çapı değişim noktası, redüksiyon yeri diğer çözümlerle aynıdır. 
Tablo 10. Geliştirilen Network yazılımı Beş borulu şebeke için çözüm sonuçları

(a)

\begin{tabular}{|c|c|c|c|c|c|c|}
\hline $\begin{array}{c}\text { Başlang1ç } \\
\text { Noktas1 } \\
\text { No }\end{array}$ & $\begin{array}{c}\text { Bitiş } \\
\text { Noktas1 } \\
\text { No }\end{array}$ & $\begin{array}{c}\text { Boru } \\
\text { İsmi }\end{array}$ & $\begin{array}{c}\text { Yap1 } \\
\text { Ad1 }\end{array}$ & $\begin{array}{c}\text { Boru } \\
\text { Uzunluğu }\end{array}$ & $\begin{array}{c}\text { Başlangıç } \\
\text { Kotu }\end{array}$ & $\begin{array}{c}\text { Bitiş } \\
\text { Kotu }\end{array}$ \\
\hline 0 & 1 & A & A(Y1) & 800 & 955 & 945 \\
\hline 1 & 2 & A & A(Y2) & 500 & 945 & 920 \\
\hline 2 & 3 & A & H1 & 300 & 920 & 940 \\
\hline 4 & 5 & Y1 & H1 & 500 & 945 & 900 \\
\hline 6 & 7 & Y2 & H1 & 800 & 920 & 945 \\
\hline
\end{tabular}

(b)

\begin{tabular}{|c|c|c|c|c|c|c|}
\hline $\begin{array}{c}\text { Başlangıç } \\
\text { Noktası No }\end{array}$ & $\begin{array}{c}\text { Bitiş } \\
\text { Noktası No }\end{array}$ & $\begin{array}{c}\text { Statik } \\
\text { Seviye } \\
(\mathrm{m})\end{array}$ & $\begin{array}{c}\text { Dinamik } \\
\text { Seviye (m) }\end{array}$ & $\begin{array}{c}\text { İstenen } \\
\text { düşü (m) }\end{array}$ & $\begin{array}{c}\text { Toplam } \\
\text { alan (ha) }\end{array}$ & Debi (1/s) \\
\hline 0 & 1 & 15 & $\mathbf{8 , 3 6}$ & 947 & 28 & 70 \\
\hline 1 & 2 & 40 & $\mathbf{3 0 , 2 4}$ & 922 & 16 & 40 \\
\hline 2 & 3 & 40 & $\mathbf{6 , 2 6}$ & 942 & 8 & 20 \\
\hline 4 & 5 & 60 & $\mathbf{4 5 , 5 2}$ & 902 & 12 & 30 \\
\hline 6 & 7 & 40 & $\mathbf{2 , 0 0}$ & 947 & 8 & 20 \\
\hline
\end{tabular}

(c)

\begin{tabular}{|c|c|c|c|c|c|c|}
\hline $\begin{array}{c}\text { Başlangıç } \\
\text { Noktası No }\end{array}$ & $\begin{array}{c}\text { Bitiş } \\
\text { Noktası No }\end{array}$ & $\begin{array}{c}\text { Boru } \\
\text { Tipi 1 }\end{array}$ & $\begin{array}{c}\text { Çap 1 } \\
(\mathrm{mm})\end{array}$ & $\begin{array}{c}\text { Uzunluk 1 } \\
(\mathrm{m})\end{array}$ & $\begin{array}{c}\text { Hız 1 } \\
(\mathrm{m} / \mathrm{s})\end{array}$ & $\begin{array}{c}\text { Hidrolik } \\
\text { Eğim }(\mathrm{m} / \mathrm{m})\end{array}$ \\
\hline 0 & 1 & PE & 280 & 800,00 & 1,32 & 0,0082948 \\
\hline 1 & 2 & PE & 250 & $326,90)$ & 0,95 & 0,0050036 \\
\hline 2 & 3 & PE & 160 & 300,00 & 1,16 & 0,0132583 \\
\hline 4 & 5 & PE & 180 & 500,00 & 1,37 & 0,0156815 \\
\hline 6 & 7 & PE & 200 & 800,00 & 0,74 & 0,0040493 \\
\hline
\end{tabular}

(d)

\begin{tabular}{|c|c|c|c|c|c|c|c|}
\hline $\begin{array}{c}\text { Başlangıç } \\
\text { Noktası No }\end{array}$ & $\begin{array}{c}\text { Bitiş } \\
\text { Noktas1 } \\
\text { No }\end{array}$ & $\begin{array}{c}\text { Boru } \\
\text { Tipi 2 }\end{array}$ & $\begin{array}{c}\text { Çap 2 } \\
(\mathrm{mm})\end{array}$ & $\begin{array}{c}\text { Uzunluk2 } \\
(\mathrm{m})\end{array}$ & $\begin{array}{c}\text { Hız 2 } \\
(\mathrm{m} / \mathrm{s})\end{array}$ & $\begin{array}{c}\text { Hidrolik } \\
\begin{array}{c}\text { Eğim } \\
(\mathrm{m} / \mathrm{m})\end{array}\end{array}$ & $\begin{array}{c}\text { Hidrant } \\
\text { Alan1 } \\
(\mathrm{ha})\end{array}$ \\
\hline 0 & 1 & & & & & & 0 \\
\hline 1 & 2 & PE & 225 & 173,10 & 1,17 & 0,0086 & 0 \\
\hline 2 & 3 & & & & & & 8 \\
\hline 4 & 5 & & & & & & 12 \\
\hline 6 & 7 & & & & & & 8 \\
\hline
\end{tabular}


(e)

\begin{tabular}{|c|c|c|c|}
\hline $\begin{array}{c}\text { Başlangıç } \\
\text { Noktası No }\end{array}$ & $\begin{array}{c}\text { Bitiş } \\
\text { Noktas1 No }\end{array}$ & $\begin{array}{c}\text { Boru } \\
\text { Bedeli 1 }\end{array}$ & $\begin{array}{c}\text { Boru } \\
\text { Bedeli 2 }\end{array}$ \\
\hline 0 & 1 & 42216,00 & \\
\hline 1 & 2 & 14252,70 & 6333,85 \\
\hline 2 & 3 & 6504,00 & \\
\hline 4 & 5 & 12835,00 & \\
\hline 6 & 7 & 23728,00 & \\
\hline
\end{tabular}

\section{SONUÇLAR}

$\mathrm{Bu}$ çalışmada iki farklı algoritma; heuristik tabanlı dinamik programlama ve simplex yöntemleri kullanılmış ve sonuçlar; DSİ Network ve Excel programı ile karşılaştırılmıştır. Simplex algoritmasının daha iyi ve daha hızlı sonuç verdiği tespit edilmiştir. Her iki algoritmanın sonuçları DSİ tarafindan kullanılan DSI Network yazılımı sonuçları ile karşılaştırılmıştır. Yapılan karşılaştırmada Simplex yöntemi sonuçlarının heuristik tabanlı dinamik programlama sonuçlarına göre daha ekonomik ve DSI Network yazılımı sonuçlarına daha yakın olduğu tespit edilmiştir. Bu çalışmada Simplex yöntemi kullanılarak geliştirilen algoritmanın sonuçları beş borulu bir şebeke için DSI Network ve Excel yazılımları sonuçları ile test edilmiştir.Üç yazılım sonucunun, boru değişim noktalarının bile aynı olmasından yola çıkılarak birebir aynı olduğu tespit edilmiştir.

Geliştirilen algoritma kullanılarak elde edilen yazılım ile ülkemize sulama şebekeleri çözümü algoritması bilgisi aktarılmış, DSİ tarafından 1986 yılında Fransız bir firmaya yaptırılmış olan yazılıma bağımlılıktan kurtulunmuştur.

Ekonomik sulamada borulu şebeke tasarımının önemli iki kademesi; boru güzergahlarının doğru seçilmesi ve boru çapları optimizasyon hesaplarının doğru yapılmasıdır. Bu çalışma ile yeni bir sulama şebekesi yazılımı ülkemize kazandırılmıştır. Simplex yöntemini kullanan bu yazılım, borulu sulama şebekelerini çözen bir araç olarak DSİ Genel Müdürlügü ve Bölge Müdürlükleri tarafından kullanılmaktadır. Borulu sulama şebekelerinin güzergah tasarımının daha sağlıklı yapılabilmesi için yazılımın Coğrafi Bilgi Sistemleri (CBS) tabanlı çalışmalarına devam edilmektedir. Yeni yazılımın CBS tabanlı çalışan versiyonu ile farklı güzergahlara göre en ekonomik şebeke çözümlerine ulaşılabilecektir. Farklı boru güzergahları için maliyet karşılaştırması yapılarak en uygun güzergah çözümü sunulabilecektir.

Yazılımın geliştirilmesi ile Türkiye'deki sulama sistemleri çözümleri farklı ülkelere de taşınabilecektir. Mevcut işletmede olan sorunlu çalışan sulama şebekelerinin sorunlarının çözümünde bu çalışmada geliştirilen yazılım kullanılabilecektir. Bu yazılım kullanım kolaylığı ve kolay ulaşılabilirliği sayesinde daha ekonomik borulu sulama şebekeleri tasarlanabilecektir. Çözümlerin hazırlanması ve kontrolü çok kısa bir süre de yapilabilecektir. 


\section{Kaynaklar}

[1] Adebe A.J., Solomatine D.P. 1998. Application of global optimization to the design of pipe networks

[2] Alandi P.P., Alvarez J.F.O., Benito J.M.T.M., 2006, Optimization of irrigation water distribution networks, layout included, , Science Direct

[3] Clements J.A., 1989, "Process Capability Calculations for non-normal distributions", Quality Progress, Vol. 22, pp.95-100

[4] Collins M.,Cooper L., Helgason R., Kennington J., LeblancL. 1978, Solving the Pipe Network Analysis Problem Using Optimization Techniques,

[5] Çakmak B., Yıldırım M., Aküzüm T, 2008, Türkiye'de Tarımsal Sulama Yönetimi, Sorunlar ve Çözüm Önerileri, TMMOB 2. Su Politikaları Kongresi.

[6] Dal H., 2014. Sulama Şebekelerini Projelendirme Esasları Hakkında Genel Bilgiler, DSİ Proje ve İnşaat Dairesi Başkanlığı Proje Semineri Ders Notları

[7] Darama, Y., 2009, Introduction to Irrigation and Drainage Engineering”, Lecture notes, METU, Civil Engineering Department, $3^{\text {rd }}$ Edition, Ankara, Turkey

[8] DSİ'ce İşletilen ve Devredilen Sulama Tesisleri 2005 Yılı Değerlendirme Raporu. 2006, DSİ Gn. Md., İşletme ve Bakım Dairesi Başkanlığı, Ankara.

[9] DSİ, 50.Yılında DSİ. 2004, Enerji ve Tabi Kaynaklar Bakanlığı DSİ Genel Müdürlüğü, DSİ İdari ve Mali İşler Daire Başkanlı̆̆ı, Basım ve Fotofilm Şb.Md.84s. Ankara.

[10] Eiger G., Shamir U., Ben-Tal A. 1994, Optimal design of water distribution networks Water Resources Research, Vol. 30 No:9 Pages 2637-2646

[11] Jourden L., Corne D.W., Savic D. A Walters G., 2006, LEMMO: hybridising rule induction and NSGA II for multi-objective optimization problems. In Proc of the Eight International Conference on Computing and Control for the Water Industry, vol $2 \mathrm{pp}$ $45-50$

[12] Knowles J., 2006, ParEGO: a hybrid algorithm with on-line landscape approximation for expensive multiobjective optimization problems.IEEE Transactiona on Evolutionary Computation 10(1),50-66

[13] Labye, Y.; Olson, M.A.; Galand, A. y Tsiourtis, N.,1988. "Design and optimization of irrigation distributions networks." Irrigation and Drainage $n^{\circ} 44$. FAO. Roma

[14] Mandl C.E., 1980, A survey of mathenatical optimization models and algorithms for designing and extending irrigation and wastewater networks, Forschungsbericht /Research Memorandum No:157

[15] Pierro F., Khu S., Savic D., Luigi B. 2008, Efficient multi-objective optimal design of water distrubution networks on a budget of simulations using hybrid algorithms, Enviromental Modelling \&Software 
[16] Rossman, L.A. 1993. EPANET, User's Manual Risk Reduction Engg.Laboratory, Office of Research \&Devt, U.S.Env.Protection Agency, Cincinnati, Ohio

[17] Theocharis M.E., Tzimopoulous C.D., Sakelariou M.A., Yannopoulos S.I.,Meletiou I.K., 2010, “Comparative Calculation of Irrigation Networks using Labye's Method, the linear programming, and simplied nonlinear method", Mathematical and Computer Modelling Journal, Science Direct, 51, pp. 286-295, Elsevier.

[18] Walski, 1987, T.M., Battle of the network models: Epilogue, J. Water Resour. Planning Management, ASCE, V.11382, pp. 191-203

[19] Sayan M. 2013. Sulama Şebekelerinde Esneklik (Fleksibilite) Katsayısının Hesaplanması, DSİ Proje ve İnşaat Dairesi Başkanlığı Proje Semineri Ders Notları syf. 163-168

[20] Keleş M.2013. Basınçlı Sulama Şebekelerinde Network Optimizasyon Programının Kullanılması ve Sonuçlarının Değerlendirilmesi 2013. DSİ Proje ve İnşaat Dairesi Başkanlığı Proje Semineri Ders Notları syf. 71-87

Ek 1 : Beş Borulu Şebeke için DSI Network Yazılımı Sonucu - 2. Boru Redüksiyon Yeri

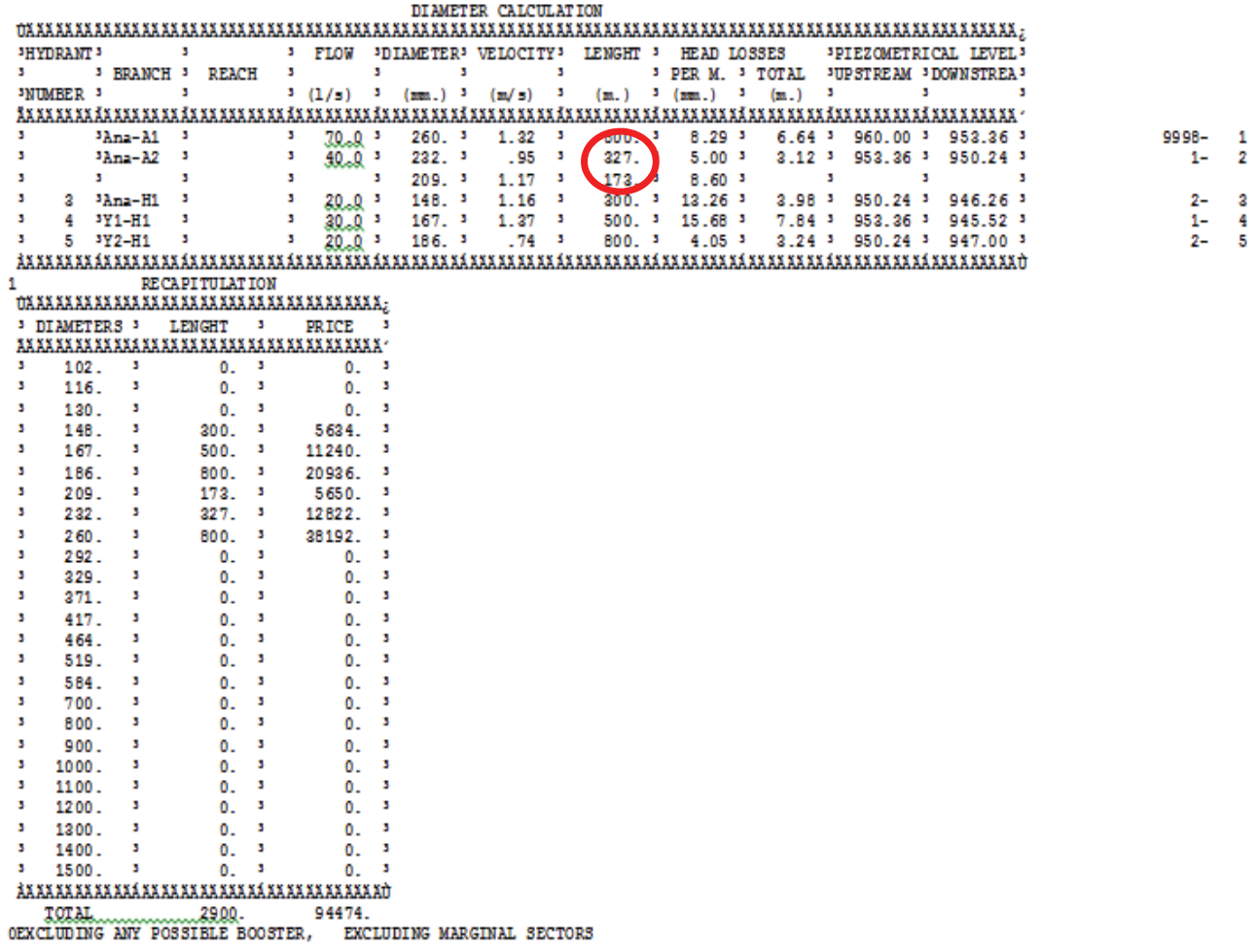

